\title{
Development of Low Rigidity $\beta$-type Titanium Alloy for Biomedical Applications
}

\author{
Mitsuo Niinomi ${ }^{1}$, Tomokazu Hattori ${ }^{2}$, Keizo Morikawa ${ }^{3}$, Toshihiro Kasuga ${ }^{4}$, \\ Akihiro Suzuki ${ }^{5}$, Hisao Fukui ${ }^{6}$ and Sigeo Niwa ${ }^{3}$ \\ ${ }^{1}$ Department of Production Systems Engineering, Toyohashi University of Technology, Toyohashi 441-8580, Japan \\ ${ }^{2}$ Department of Materials Science and Engineering,Faculty of Science and Technology, Meijo University, Nagoya 468-8502, Japan \\ ${ }^{3}$ Department of Orthopaedic Surgery, Aichi Medical University, Nagakute, Aichi 480-1195, Japan \\ ${ }^{4}$ Department of Materials Scioence, Nagoya Institute of Technology, Nagoya 466-8555, Japan \\ ${ }^{5} R \& D$ Laboratory, Daido Steel Co., Ltd., Nagoya 457-8545, Japan \\ ${ }^{6}$ Department of Dental Materials Science, School of Dentistry, Aichi-Gakuin University, Nagoya 464-8650, Japan
}

\begin{abstract}
The low rigidity type titanium alloy, Ti-29Nb-13Ta-4.6Zr was designed, and then the practical level ingot of the alloy was successfully fabricated by Levicast method. The mechanical and biological compatibilities of the alloys were investigated in this study. The following results were obtained. The mechanical performance of tensile properties and fatigue strength of the alloy are equal to or greater than those of conventional biomedical Ti-6Al-4V ELI. Young's modulus of the alloy is much lower than that of Ti-6Al-4V ELI, and increases with the precipitation of $\alpha$ phase or $\omega$ phase in the $\beta$ matrix phase. The compatibility of the alloy with bone of the alloy is excellent. Low rigidity of the alloy is effective to enhance the healing of bone fracture and remodeling of bone. The bioactive coating layer of hydroxyapatite can be formed on the alloy.
\end{abstract}

(Received May 15, 2002; Accepted July 26, 2002)

Keywords: titanium-29niobium-13tantalum-4.6zirconium, $\beta$-type titanium alloy, low rigidity, biomedical application, biocompatibility, hydroxyapatite

\section{Introduction}

Pure titanium and $\alpha+\beta$ type Ti-6Al-4V ELI alloys are currently used widely as structural biomaterials for instruments for replacing failed hard tissues such as artificial hip joints, dental implants, etc. because they have excellent specific strength and corrosion resistance, no allergic problems and the greatest biocompatibility among the metallic biomaterials. They occupy almost all market of titanium biomaterials. However, other new titanium alloys for biomedical applications have been registered in ASTM standardizations after pure titanium and Ti-6Al-4V ELI being registered. Very recently, other new titanium alloys for biomedical applications such as $\beta$ type Ti-15Mo ${ }^{1)}$ have been registered in ASTM standardizations. $\beta$ type $\mathrm{Ti}-35 \mathrm{Nb}-7 \mathrm{Zr}-5 \mathrm{Ta},{ }^{2)}$ and $\alpha+\beta$ type Ti-3Al-2.5 $\mathrm{V}^{3)}$ are on the way to being registered in ASTM standardizations. Nowadays, both $\alpha+\beta$ type $^{4)}$ and $\beta$ type ${ }^{5)}$ titanium alloys composed of non-toxic and non-allergic elements are being developed energetically.

$\beta$ type titanium alloys have been developed or are being developed in order to obtain low rigidity titanium alloys because the low rigidity is effective to enhance the bone healing and remodeling. The rigidity of $\alpha+\beta$ type titanium alloys is still much greater than that of cortical bone although the rigidity of titanium alloys is much smaller than that of $\mathrm{Co}-$ Cr type alloys and SUS stainless steels used for biomedical applications. ${ }^{6}$ ) The recent trend in research and development of titanium alloys for biomedical applications is to develop the low rigidity $\beta$ type titanium alloys composed of non-toxic and non-allergic elements with excellent mechanical properties and workability. ${ }^{5)}$

According to this concept, low rigidity $\beta$ type titanium al- loy composed of non-toxic and non-allergic elements with excellent mechanical properties and workability for biomedical applications was designed in this study. Then, the basic mechanical biocompatibility and biological compatibility of the designed alloy were investigated.

\section{Experimental Procedures}

\subsection{Alloying elements and alloy composition}

Non-toxic elements were selected based on the data of cyto-toxicity of pure metals ${ }^{7)}$ and the data of polarization resistance and biocompatibility of representative metallic biomaterials and pure metals. ${ }^{8)}$ Finally, $\mathrm{Nb}$, Ta and $\mathrm{Zr}$ were selected as alloying elements for Ti. From the point of view of mechanical biocompatibility, low rigidity is favorable. Therefore, $\mathrm{Ti}-\mathrm{Nb}-\mathrm{Ta}-\mathrm{Zr}$ system $\beta$-type titanium alloys were determined to be developed in this study. The compositions of the candidate alloys were determined using the d-electron alloy design method developed by Morinaga et al. ${ }^{9)}$ Finally, the most expected alloy for the practical use for biomedical applications was found to be $\mathrm{Ti}-29 \mathrm{Nb}-13 \mathrm{Ta}-4.6 \mathrm{Zr}$ based on the balance of strength and ductility balance obtained from tensile tests on the specimens fabricated from the laboratory size ingot (around $45 \mathrm{~g}$ ) made by tri-arc furnace. ${ }^{5)}$

\subsection{Melting and processing}

The practical level ingot of $\mathrm{Ti}-29 \mathrm{Nb}-13 \mathrm{Ta}-4.6 \mathrm{Zr}$ around $20 \mathrm{~kg}$ was fabricated by the levitation casting (Levicast) method. ${ }^{10)}$ The ingot was firstly forged at $1223 \mathrm{~K}$ and then forged at $1123 \mathrm{~K}$ to finish the bars with a diameter of $20 \mathrm{~mm}$ or $12 \mathrm{~mm}$. 


\subsection{Material preparation}

The forged bars with a diameter of $20 \mathrm{~mm}$ were cold rolled by a reduction of $87.5 \%$ to plates with a thickness of $2.5 \mathrm{~mm}$ at room temperature in air. The rolled plates were conducted with solution treatment at $1063 \mathrm{~K}$ for $3.6 \mathrm{ks}$ followed by water quenching (ST), and then aged (STA) at various temperatures. Some plates were directly aged at various temperatures after cold rolling.

On the other hand, the forged bars with a diameter of $12 \mathrm{~mm}$ were conducted with solution treatment at $1063 \mathrm{~K}$ for $3.6 \mathrm{ks}$ followed by water quenching, and then cold swaged to bars with various diameters up to $4 \mathrm{~mm}$.

\subsection{Mechanical testing}

Tensile and fatigue test specimens with a width of $1.2 \mathrm{~mm}$, a thickness of $1.5 \mathrm{~mm}$ and a cross section area of $4.5 \mathrm{~mm}^{2}$, and specimens for measuring Young's modulus with a length of $5.6 \mathrm{~mm}$, a width of $1.2 \mathrm{~mm}$ and a thickness of $1.5 \mathrm{~mm}$ were machined from the heat treated plates as for the tensile axis to be parallel to the rolling direction. The tensile test specimens with heat treatments were wet polished using waterproof emery papers up to \#1500 and then buff polished. The specimens for measuring Young's modulus were wet polished using waterproof emery papers up to $\# 1500$.

For cold swaged bars with a diameter of over $4 \mathrm{~mm}$, tensile specimens with a gage diameter of $6.35 \mathrm{~mm}$ and a gage length of 25.4 were machined as for the tensile axis to be parallel to the swaging direction. For the cold swaged bar with a diameter of $4 \mathrm{~mm}$, tensile specimens with a gage diameter of $2.4 \mathrm{~mm}$ and a gage length of $9.6 \mathrm{~mm}$ were machined as for the tensile axis to be parrarel to the swaging direction. In this case, the surface condition of the specimen was as machined.

Tensile tests were carried out using an Instron-type machine at a crosshead sped of $8.33 \times 10^{-6} \mathrm{~m} / \mathrm{s}$ in air at room temperature.

Fatigue tests were carried out using an electro-servohydraulic machine at a frequency of $10 \mathrm{~Hz}$ with a stress ratio, $R=0.1$, under the tension-tension mode in air at room temperature.

Young's modulus was measured using a resonance method in air at room temperature. For comparison, Young's modulus of Ti-6Al-4V ELI was also measured.

\subsection{Microstructual analysis}

The constituted phases of each heat-treated alloy were examined on the chuck part of the tensile specimen through an $\mathrm{X}$-ray diffraction analysis and observations using a transmission electron microscopy (TEM). X-ray analysis was carried out using a $\mathrm{Cu}$ target with an accelerating voltage of $40 \mathrm{kV}$ and a current of $30 \mathrm{~mA}$. TEM observations were carried out with an acceleration voltage of $200 \mathrm{kV}$.

\subsection{Evaluation of biological compatibility}

Columnar specimens with a size of $\phi 5 \mathrm{~mm} \times 10 \mathrm{~mm}$ were machined from the cold swaged bar of Ti-29Nb-13Ta-4.6Zr with a diameter of $5 \mathrm{~mm}$. In this case, the same size columnar specimens of commercial Ti-6Al-4V ELI and SUS 316 stainless steel for biomedical applications were also prepared. The specimens were implanted into lateral femoral condyles of Japanese white rabbits weighted 2.5 to $3.0 \mathrm{~kg}$ under intra- venous anesthesia. Then, histological observation was performed with C. M. R. (Contact Micro Radiogram) at 4 and 8 weeks after the implantation.

\subsection{Evaluation of mechanical biocompatibility}

Experimental tibia fractures were made by oscillating saw just below the tibial tuberosity of Japanese white rabbits weighed 2.5 to $3.0 \mathrm{~kg}$ under intravenous, and intramedullary fixations were performed by the rods of $\mathrm{Ti}-29 \mathrm{Nb}-13 \mathrm{Ta}-4.6 \mathrm{Zr}$ cut from the cold swaged bars, and commercial Ti-6Al-4V ELI and SUS $316 \mathrm{~L}$ stainless steel. The size of each rod was $\phi 3 \mathrm{~mm} \times 60 \mathrm{~mm}$. In order to continuously observe the state of fracture healing, $\mathrm{X}$-ray pictures were taken at every 2 weeks for 22 weeks.

\subsection{Bioactive surface modification}

The calcium phosphate invert glass was prepared using a composition of $60 \mathrm{CaO} \cdot 30 \mathrm{P}_{2} \mathrm{O}_{3} \cdot 7 \mathrm{NaO} \cdot 3 \mathrm{TiO}_{2}$ in $\mathrm{mol} \% .^{11)}$ The mixture of starting materials, which were regent-grade $\mathrm{CaCO}_{3}, \mathrm{H}_{3} \mathrm{PO}_{4}$ (85\% liquid), $\mathrm{Na}_{2} \mathrm{Co}_{3}$ and $\mathrm{TiO}_{2}$, was placed with in a Teflon beaker and stirred to make a slurry. The slurry was dried at around $473 \mathrm{~K}$. The resulting product was melted in a platinum crucible at $1623 \mathrm{~K}$ for $1.8 \mathrm{ks}$. The melt was poured on a stainless steel plate and quickly pressed by an iron plate, resulting in the formation of glasses with thickness of $0.3-1.0 \mathrm{~mm}$. $40 \mathrm{~g}$ of the glass was pulverized to a size of less than $10 \mu \mathrm{m}$ in a diameter (the average size is $1.0-1.5 \mu \mathrm{m}$ ) using a zirconia ball mill with zirconia balls in $50 \mathrm{ml}$ of water. After the pulverization, the slurry was poured into a polyethylene vessel and used for a subsequent discoating.

The as-forged bars of $\mathrm{Ti}-29 \mathrm{Nb}-13 \mathrm{Ta}-4.6 \mathrm{Zr}$ were machined into a disk shape of $18 \mathrm{~mm}$ diameter with $1 \mathrm{~mm}$ thickness and its surface was sandblasted into a roughness of around $2 \mu \mathrm{m}$. The disk was washed using aceton in an ultrasonic bath. That was subsequently dried at $373 \mathrm{~K}$. Then the disk-shaped substrate (Ti-29Nb-13Ta-4.6Zr) was dipped into the glass-powder slurry described above, that was drawn up at a speed of $1.4 \mathrm{~mm} / \mathrm{s}$ and dried at $273 \mathrm{~K}$. The glass powder layer with a thickness of around $30 \mu \mathrm{m}$ was placed on the substrate by this method. After the substrate with glass powder layer was placed in an electric furnace, that was heated at 1023 or $1073 \mathrm{~K}$ for $3.6 \mathrm{ks}$ in air and cooled to room temperature in the furnace.

Crystalline phases in the coating layer were examined by an X-ray diffraction (XRD) and the microstructure was observed by a scanning electron microscopy (SEM) incorporating X-ray microanalysis using an energy dispersive spectrometry (EDS).

The coating sample $(20 \mathrm{~mm}$ diameter $\times 1 \mathrm{~mm})$, which was prepared by heating at $1073 \mathrm{~K}$, was soaked in $50 \mathrm{ml}$ of SBF $\left(\mathrm{Ca}^{2+}: 2.5 ; \mathrm{Mg}^{2+}: 1.5 ; \mathrm{Na}^{+}: 142.0 ; \mathrm{K}^{+}: 5.0 ; \mathrm{Cl}^{-}: 148.8\right.$; $\mathrm{HCO}^{3-}: 4.2$; and $\mathrm{HPO}_{4}^{2-}: 1.0$ including trishydroxymethlaminometane; 50 and $\mathrm{HCl} ; 45.0$, in $\mathrm{mM}$ ), of which inorganic ion concentrations were adjusted to be almost equal to those of the human plasma, for 10-30 days at $310 \mathrm{~K}$. After the soaking, the surface was examined by XRD and observed by an SEM. 


\section{Results and Discussion}

\subsection{Homogeneity of ingot}

The alloy contains the elements of $\mathrm{Ta}$ and $\mathrm{Nb}$ that have greater specific gravity and higher melting points as compared with those of Ti.

The distribution of each element was checked. The distribution of each element from the top through the bottom of the ingot is shown in Fig. 1. It is clear that each element distributes homogeneously from the top to bottom of the ingot, and is in the target content value.

\subsection{Balance of strength and ductility}

The balance of tensile strength and elongation of Ti-29Nb$13 \mathrm{Ta}-4.6 \mathrm{Zr}$ conducted with various aging after solution treatment or directly after cold rolling is shown in Fig. 2 with the range of the same data of annealed Ti-6Al-4V ELI. The strength and elongation of $\mathrm{Ti}-29 \mathrm{Nb}-13 \mathrm{Ta}-4.6 \mathrm{Zr}$ can be controlled variously by conducting heat treatment or thermomechanical treatment, and is better than that of Ti-6Al-4V ELI by conducting proper heat treatment or thermomechanical treatment.

\subsection{Fatigue strength}

$\mathrm{S}-\mathrm{N}$ curves of $\mathrm{Ti}-29 \mathrm{Nb}-13 \mathrm{Ta}-4.6 \mathrm{Zr}$ in as-solutionized and aged conditions are shown in Fig. 3 with the range of S-N curves of Ti-6Al-4V ELI in aged conditions. The fatigue strength of $\mathrm{Ti}-29 \mathrm{Nb}-13 \mathrm{Ta}-4.6 \mathrm{Zr}$ is situated in the upper range of the fatigue strength of Ti-6Al-4V ELI by conducting aging after solution treatment. The fatigue strength of

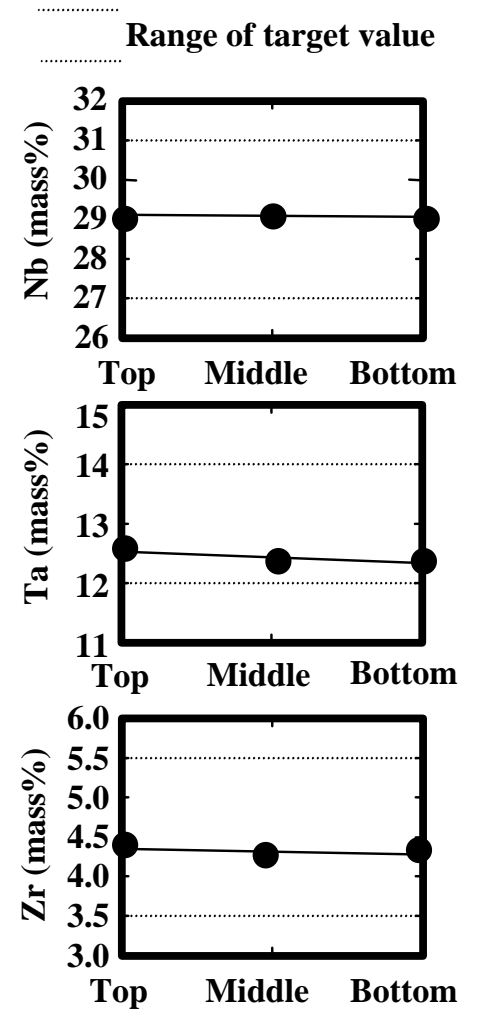

Fig. 1 Distribution of $\mathrm{Nb}$, Ta or $\mathrm{Zr}$ as a function of position in ingot of $\mathrm{Ti}-29 \mathrm{Nb}-13 \mathrm{Ta}-4.6 \mathrm{Zr}$.
Ti-29Nb-13Ta-4.6Zr will be more improved by further investigations on the effects of aging conditions on the fatigue strength.

\subsection{Young's modulus}

Young's moduli of Ti-29Nb-13Ta-4.6Zr and Ti-6Al-4V ELI are shown in Fig. 4. For Ti-29Nb-13Ta-4.6Zr, Young's moduli in various aging conditions are also shown in Fig. 4. Young's modulus of $\mathrm{Ti}-29 \mathrm{Nb}-13 \mathrm{Ta}-4.6 \mathrm{Zr}$ is much smaller than that of Ti-6Al-4V ELI even in the case of the greatest value, that is, in aged conditions. In the case of the smallest Young's modulus, aroud $65 \mathrm{GPa}$ is obtained in as-solutionized conditions (ST). This value of Young's modulus is nearly the half of that of Ti-6Al-4V. Furthermore, Young's modulus of $\mathrm{Ti}-29 \mathrm{Nb}-13 \mathrm{Ta}-4.6 \mathrm{Zr}$ is changed by aging treatment because $\alpha$ or $\omega$ phase with greater Young's modulus comparing with

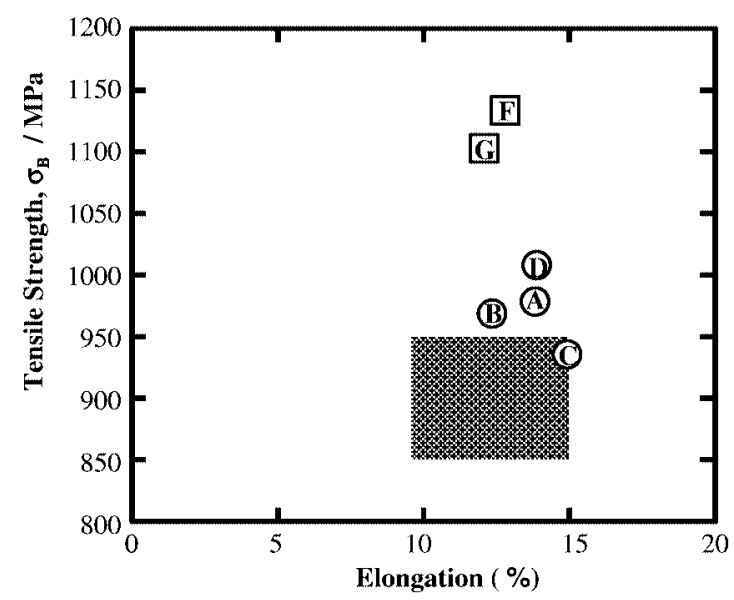

Fig. 2 Balance of tensile strength and elongation of Ti-6Al-4V ELI and $\mathrm{Ti}-29 \mathrm{Nb}-13 \mathrm{Ta}-4.6 \mathrm{Zr}$ conducted with various aging treatment after solution treatment or directly after cold rolling. (aged after solution treatment), $\bigcirc$; Ti-29Nb-13Ta-4.6Zr (aged after solution treatment), A; $(1033 \mathrm{~K}, 1.8 \mathrm{ks}+673 \mathrm{~K}, 259.2 \mathrm{ks}), \mathrm{B} ;(1033 \mathrm{~K}$, $1.8 \mathrm{ks}+598 \mathrm{~K}, 100.8 \mathrm{ks}), \mathrm{C} ;(1033 \mathrm{~K}, 1.8 \mathrm{ks}+723 \mathrm{~K}, 259.2 \mathrm{ks}), \mathrm{D} ;(1063 \mathrm{~K}$, $1.8 \mathrm{ks}+673 \mathrm{~K}, 259.2 \mathrm{ks}), \square$; Ti-29Nb-13Ta-4.6Zr (aged after directly cold rolling (C. W)), F; (C. W. +723 K, $100.8 \mathrm{ks)}$ and G; (C. W. +723 K, $259.8 \mathrm{ks})$.

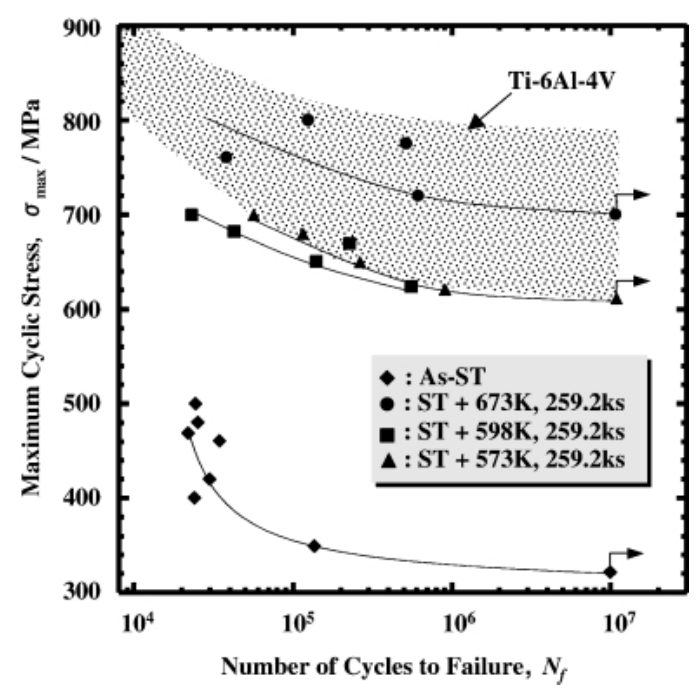

Fig. $3 \mathrm{~S}-\mathrm{N}$ curve of $\mathrm{Ti}-29 \mathrm{Nb}-13 \mathrm{Ta}-4.6 \mathrm{Zr}$ conducted with each heat treatment and range of S-N curves of Ti-6Al-4V. 
$\beta$ phase precipitates in $\beta$ matrix phase as will be mentioned in the Section 3.5. Therefore, Young's modulus of Ti-29Nb$13 \mathrm{Ta}-4.6 \mathrm{Zr}$ can be controlled by aging treatment.

\subsection{Microstructure}

Microstructure of $\mathrm{Ti}-29 \mathrm{Nb}-13 \mathrm{Ta}-4.6 \mathrm{Zr}$ conducted with solution treatment showed only $\beta$ phase with an average diameter of $20 \mu \mathrm{m}$. In Ti-29Nb-13Ta-4.6Zr aged at a temperature between $573 \mathrm{~K}$ and $673 \mathrm{~K}$ after solution treatment, it was difficult to observe precipitated phases by light microscope because they were too fine to identify. Therefore, X-ray analysis and TEM observations were carried out to identify the phases in aged alloys.

X-ray diffraction profiles of the alloy conducted with solution treatment, and aging treatments are shown in Fig. 5 revealing that $\alpha$ phase or $\alpha$ and $\omega$ phases are precipitated in

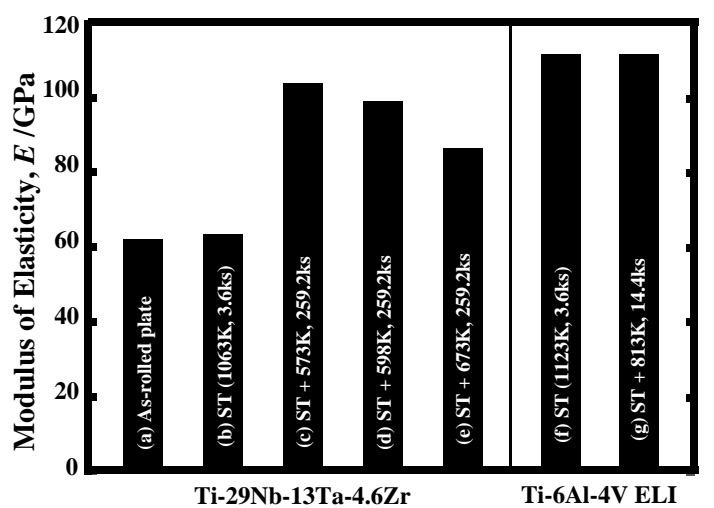

Fig. 4 Young's moduli of $\mathrm{Ti}-29 \mathrm{Nb}-13 \mathrm{Ta}-4.6 \mathrm{Zr}$ in as-rolled, as-solutionized (ST) and aged conditions, and Ti-6Al-4V ELI in as-solutionaized and aged (STA) conditions.
Ti-29Nb-13Ta-4.6Zr aged at a temperature between $573 \mathrm{~K}$ and $673 \mathrm{~K}$ after solution treatment.

Figure 6 shows TEM micrograph and diffraction pattern of $\mathrm{Ti}-29 \mathrm{Nb}-13 \mathrm{Ta}-4.6 \mathrm{Zr}$ aged at $673 \mathrm{~K}$ for $259.2 \mathrm{ks}$ after solution treatment. Fine plate like $\alpha$ phases with two variants are precipitated homogeneously in $\beta$ phase. The $\alpha$ phases

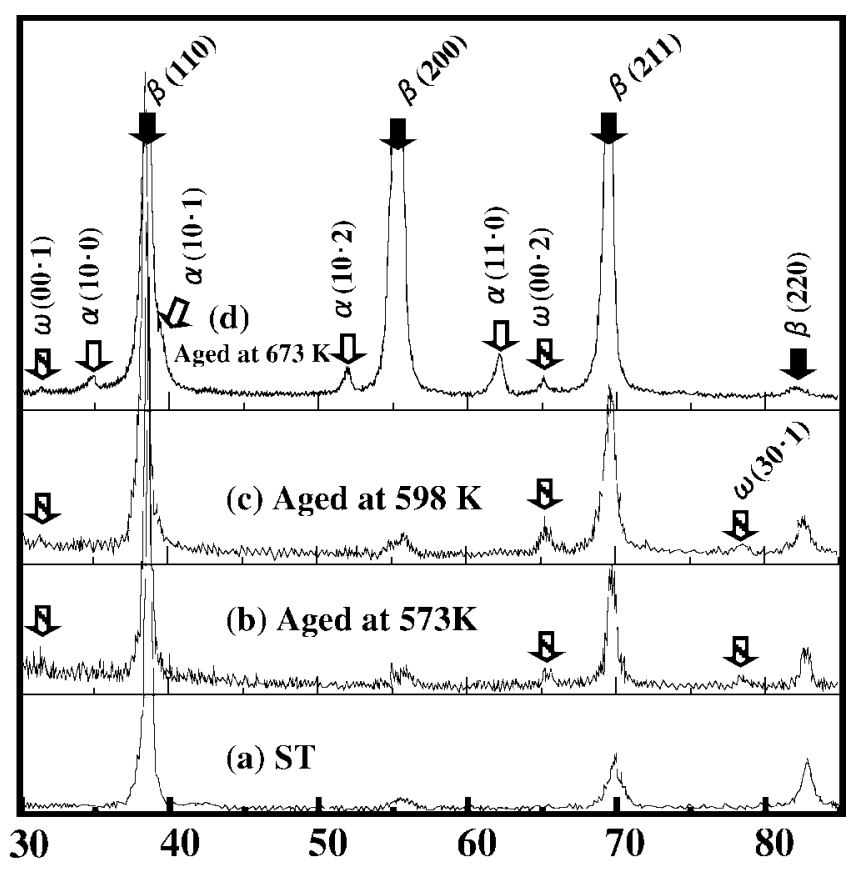

Diffraction Angle, $2 \theta$

Fig. 5 X-ray diffraction profile of Ti-29Nb-13Ta-4.6Zr conducted with (a) solution treatment (ST), or aged for $259.2 \mathrm{ks}$ at (b) $573 \mathrm{~K}$, (c) $598 \mathrm{~K}$ or (d) $673 \mathrm{~K}$ after ST. (a)

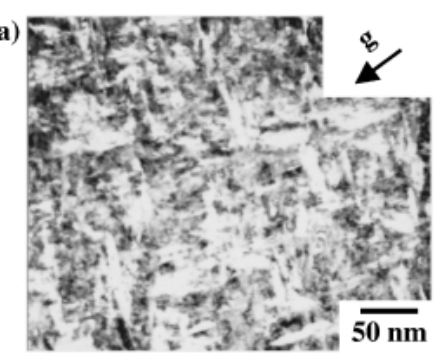

(b)

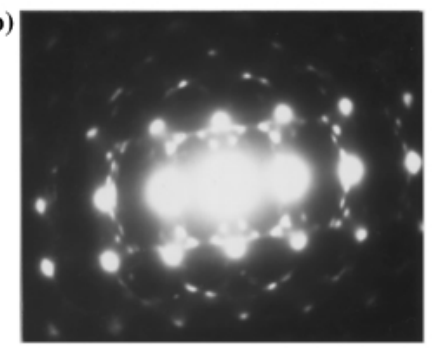

(c) $\overline{2} 00$

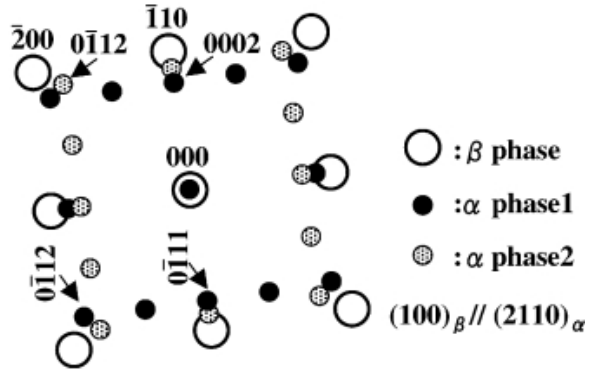

Fig. 6 Transmission electron micrograph, diffraction pattern and key diagram of Ti-29Nb-13Ta-4.6Zr aged at $673 \mathrm{~K}$ for $259.2 \mathrm{ks}$ after solution treatment at $1063 \mathrm{~K}$ for $3.6 \mathrm{ks}$; (a) dark field image of $\alpha$ phase, (b) diffraction pattern and (c) key diagram.

(a)

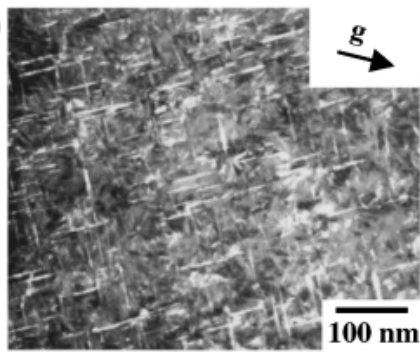

(b)

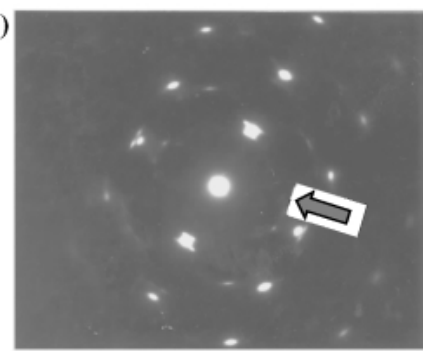

(c)

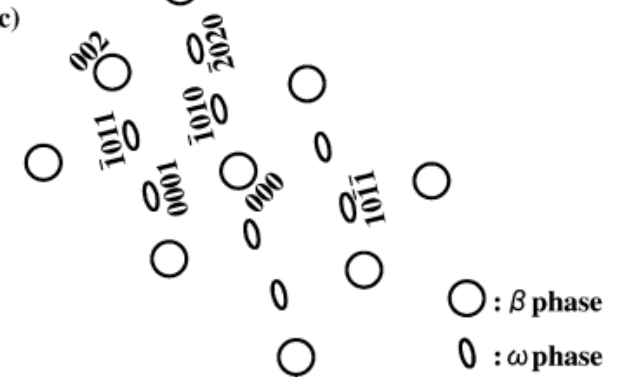

Fig. 7 Transmission electron micrograph, diffraction pattern and key diagram of $\mathrm{Ti}-29 \mathrm{Nb}-13 \mathrm{Ta}-4.6 \mathrm{Zr}$ aged at $673 \mathrm{~K}$ for $259.2 \mathrm{ks}$ after solutionizing at $1063 \mathrm{~K}$ for $3.6 \mathrm{ks}$. Arrow shows $\omega$ phase spot; (a) dark field image of w phase, (b) diffraction pattern, (c) key diagram. 
with two variants have a relation of crystal orientation rotated around 90 degrees to $\beta[100]$ phase. In addition, the precipitation of $\omega$ phase is identified using the TEM diffraction pattern shown in Fig. 7.

Therefore, the increasing strength and fatigue strength of the alloy result from the precipitation of $\alpha$ phases or $\alpha$ and $\omega$ phases in the $\beta$ matrix phase.

\subsection{Tensile properties of cold swaged alloy}

Tensile properties of cold swaged Ti-29Nb-13Ta-4.6Zr conducted with solution treatment are shown in Fig. 8 as a function of cold work ratio. Tensile strength, $\sigma_{\mathrm{B}}$, and $0.2 \%$ proof stress, $\sigma_{0.2}$, increase with increasing cold work ratio. The strength of the alloy at the greatest cold work ratio reaches a similar value of conventional Ti-6Al-4V ELI. Elongation and reduction of area decrease at about $20 \%$ cold work ratio, and are then almost constant with cold work ratio. For example, the elongation at the greatest cold work ratio is over $15 \%$, which is a relatively greater value of elon-

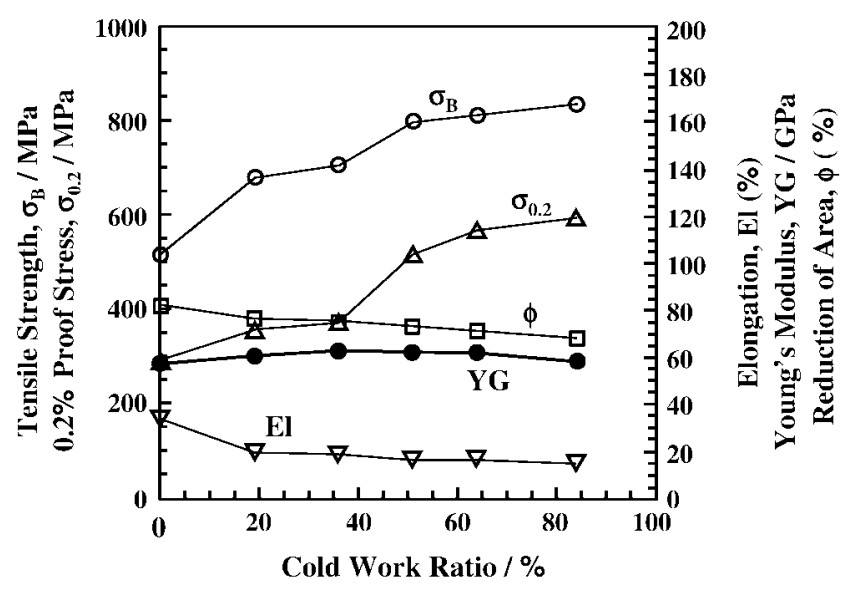

Fig. 8 Tensile properties of cold swaged bar as a function of cold work ratio. gation. Young's modulus is almost constant with increasing cold work ratio. Therefore, the strength of Ti-29Nb-13Ta$4.6 \mathrm{Zr}$ can be increased up to the equivalent strength value of conventional Ti-6Al-4V ELI with keeping Young's modulus low constant value by cold working.

\subsection{Biological compatibility \\ 3.7.1 Biocompatibility with bone}

The contact micro radiogram (C. M. R) of the boundaries of bone and Ti29Nb-13Ta-4.6Zr, Ti-6Al-4V or SUS $316 \mathrm{~L}$ stainless steel implanted into lateral femoral condyles of the rabbit is shown in Fig. 9. The each specimen is surrounded by newly formed bone, and the bone tissue shows direct contact partially with specimen. However, the extent of the direct contact is greater in $\mathrm{Ti}-29 \mathrm{Nb}-13 \mathrm{Ta}-4.6 \mathrm{Zr}$ as compared with Ti-6Al-4V and SUS $316 \mathrm{~L}$ stainless steel. Therefore, the biocompatibility of $\mathrm{Ti}-29 \mathrm{Nb}-13 \mathrm{Ta}-4.6 \mathrm{Zr}$ with bone is excellent.

\subsubsection{Effect of low rigidity}

In order to confirm the advantage of low rigidity for bone healing and remodeling, using rabbits, experimental tibial fracture was made by oscillating saw at just below the tibial tuberosity, and intramedullary rod made of low rigidity Ti29Nb-13Ta-4.6Zr, Ti-6Al-4V ELI or SUS 316 L stainless steel was driven into the intramedullary canal to fix the fracture. The observation of the state of bone healing, remodeling and atrophy was contoinuouly done with taking X-ray picture every 2 weeks up to 22 weeks. The results are shown in Figs. 10(a) and (b).

The outline of fracture callus is very smooth with bone remodeling in Ti-29Nb-13Ta-4.6Zr. Similar phenomenon is observed at 8 weeks in Ti-6Al-4V ELI and SUS 316L. In $\mathrm{Ti}-29 \mathrm{Nb}-13 \mathrm{Ta}-4.6 \mathrm{Zr}$, the amount of the fracture callus is relatively small, and gradually decreses from 6 weeks, and then there are no traces of fracture at 10 weeks after the fixation. After 10 weeks, no changes can be observed up to 18 weeks. However, a little atrophic change is observed at the posterior tibial bone after 20 weeks. In Ti-6Al-4V ELI, the callus for-

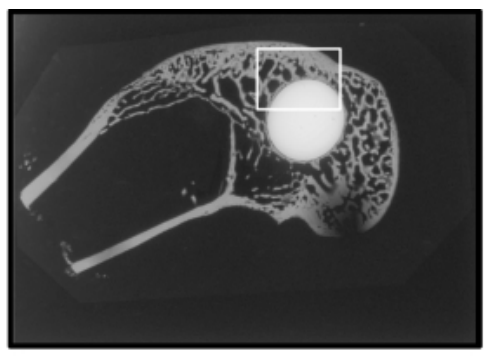

\section{Observation of tissue reaction and bone formation}

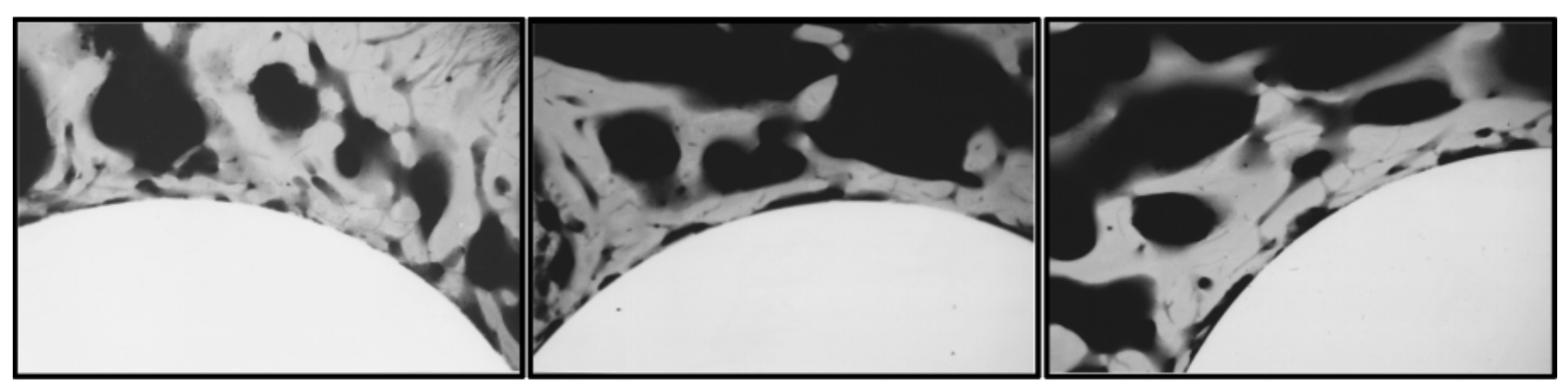

Ti-29Nb-13Ta-4.6Zr

Ti-6Al-4V ELI

SUS 316L stainless steel

Fig. 9 C. M. R. photograph of boundary of each specimen and bone at 8 weeks after implantation. 


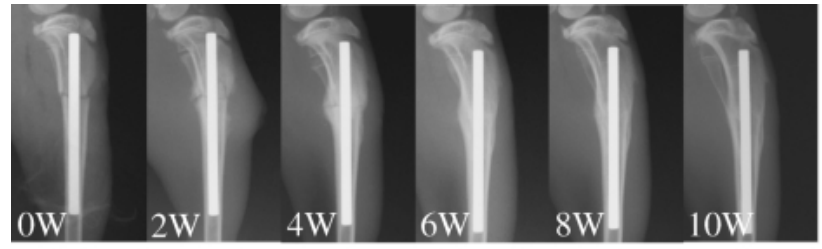

(a) $\mathrm{Ti}-29 \mathrm{Nb}-13 \mathrm{Ta}-4.6 \mathrm{Zr}$

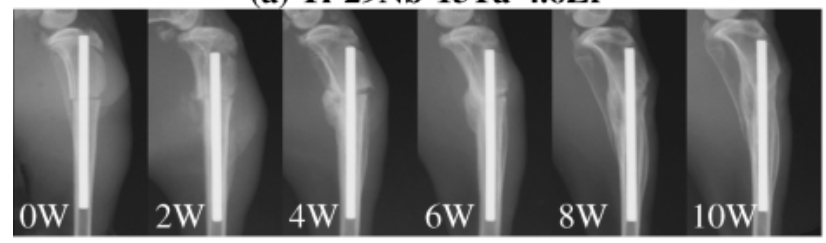

(b) Ti-6Al-4V ELI

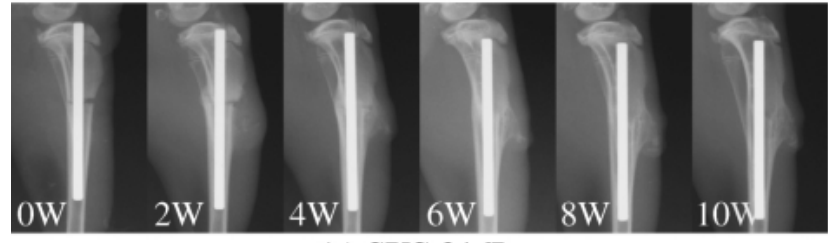

(c) SUS 316L

(A)

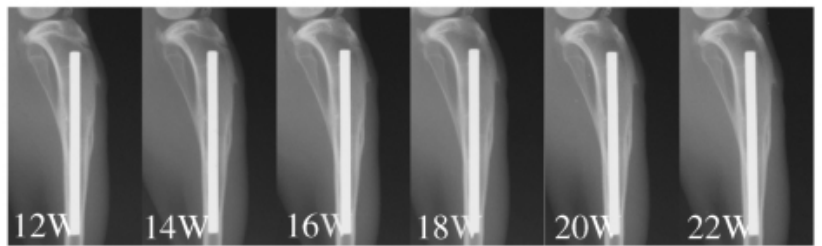

(a) Ti-29Nb-13Ta-4.6Zr

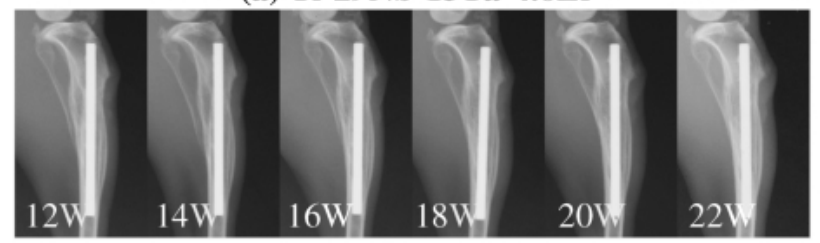

(b) Ti-6Al-4V ELI

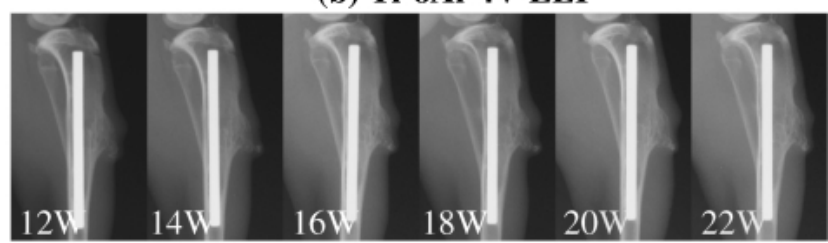

(c) SUS 316L

(B)

Fig. 10 Healing process of bone fracture (A) from 0 to 10 weeks and (B) from 12 to 22 weeks after surgery.

mation and the bone remodeling are almost similar to those in $\mathrm{T}-29 \mathrm{Nb}-13 \mathrm{Ta}-4.6 \mathrm{Zr}$, but slower as compared with $\mathrm{T}-29 \mathrm{Nb}-$ 13Ta-4.6Zr. A little atrophic change is observed at 18 weeks. In SUS 316 L stainless steel, a large amount of the fracture callus is observed, and remains up to the end of the follow up period. Bone atrophy seems to be occurring at the posterior proximal tibial bone at 10 weeks, and becomes obvious every 2 weeks. The posterior tibial bone becomes to be very thin at 22 weeks. Therefore, low rigidity titanium alloy, Ti-29Nb$13 \mathrm{Ta}-4.6 \mathrm{Zr}$, is found to improve the load transmission issue of the current metal implants with the high rigidity.

\subsection{Bioactive surface coating layer}

The coating layer formed on $\mathrm{Ti}-29 \mathrm{Nb}-13 \mathrm{Ta}-4.6 \mathrm{Zr}$ by heating the calcium phosphate invert glass at $1023 \mathrm{~K}$ was easily peeled off by a peeling test using a commercial adhesive tape. On the other hand, the coating layer obtained by heating at $1073 \mathrm{~K}$ was not peeled off by a peeling test using a commercial adhesive tape, and furthermore did not peel off even after the large deformation of the titanium alloy. Therefore, the coating layer was bonded strongly with the substrate (Ti$29 \mathrm{Nb}-13 \mathrm{Ta}-4.6 \mathrm{Zr})$.

The SEM micrograph of the cross section of the coating layer obtained by heating at $1073 \mathrm{~K}$ is shown in Fig. 11. The coated layer contains many pores with a size of several micrometers. The thickness of the layer is $10 \mu \mathrm{m}-$ $20 \mu \mathrm{m}$. No cracks and defects are observed. The joining of coated layer and substrate is successfully accomplished in this study. X-ray profiles of the surface of the coated Ti-29Nb$13 \mathrm{Ta}-4.6 \mathrm{Zr}$ heated at $1023 \mathrm{~K}$ or $1073 \mathrm{~K}$ is shown in Fig. 12. TCP $\left(\beta\right.$-tricalcium phosphate; $\left.\beta-\mathrm{Ca}_{3}\left(\mathrm{PO}_{4}\right)_{2}\right)$ and CPP $(\beta$ $\mathrm{Ca}_{2} \mathrm{P}_{2} \mathrm{O}_{7}$ ) crystals are precipitated in the layer on the substrate heated at $1023 \mathrm{~K}$. In this case, the coated layer had no bond with the substrate as stated above. On the other hand, fine joining was accomplished by heating at $1073 \mathrm{~K}$ also stated

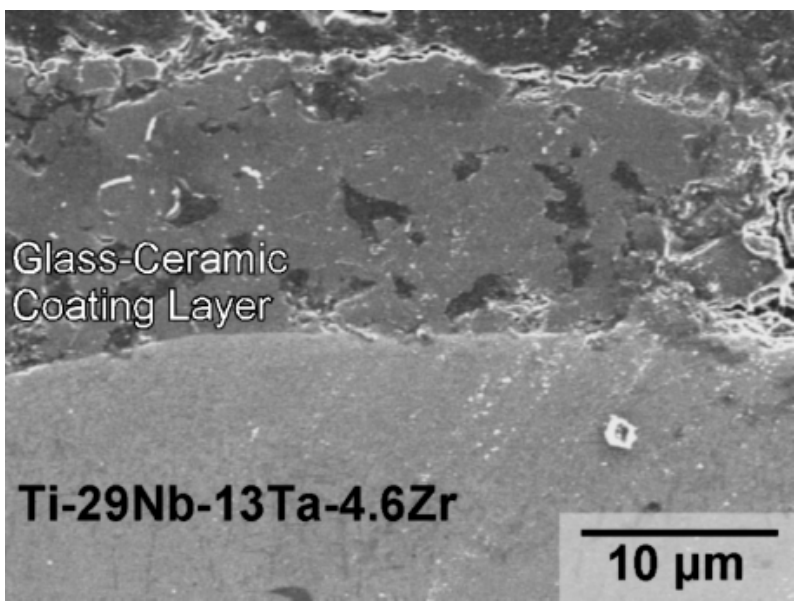

Fig. 11 SEM micrograph of cross section of coating layer obtained by heating at $1073 \mathrm{~K}$ for $3.6 \mathrm{ks}$ in air.

above. The coating layer obtained by heating at $1073 \mathrm{~K}$ consists predominantly of TCP phase with trace amounts of CPP and $\mathrm{TiO}_{2}$ crystalline phases. When the glass powders placed on the alloy were heated at $1073 \mathrm{~K}$ under the reduced pressure around $10 \mathrm{~Pa}$, no joining between the glass-ceramic layer and the alloy was accomplished. The surface of the alloy is oxidized during heating in air. Therefore, it is considered that the thin oxide layer formed on the metallic substrate plays an important role in the formation of the fine glass-ceramic coating.

X-ray profiles of the surface of the glass-ceramic coating after soaking in SBF for 10-30 days are shown in Fig. 13. After the 10 days soaking, a new peak at $2 \theta \approx 25.8^{\circ}$ due to hydroxyapatite, HA, appeared. In the pattern after soaking for 20 and 30 days, broad peaks due to HA around $2 \theta \approx 32^{\circ}$ are seen. Numerous depositions can be observed on the surface 


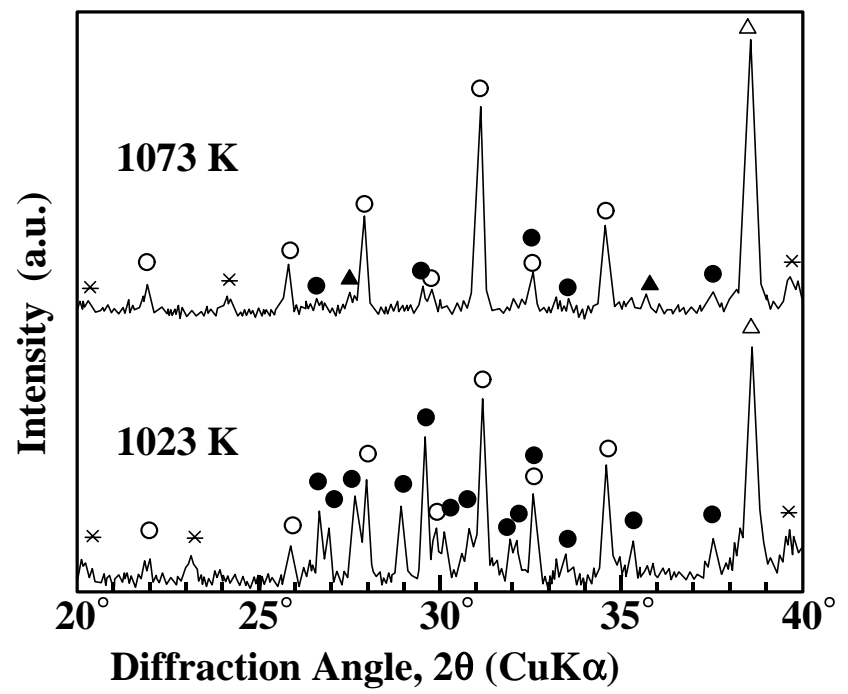

Fig. 12 X-ray diffraction patterns of coating layers on the specimens prepared by heating at $1023 \mathrm{~K}$ and $1073 \mathrm{~K}$ for $3.6 \mathrm{ks}$ in air; $\bigcirc$ : TCP, $\bigcirc$ : CPP, $\boldsymbol{\Delta}$ : $\beta$-Ti, and $*$ : unknown phase.

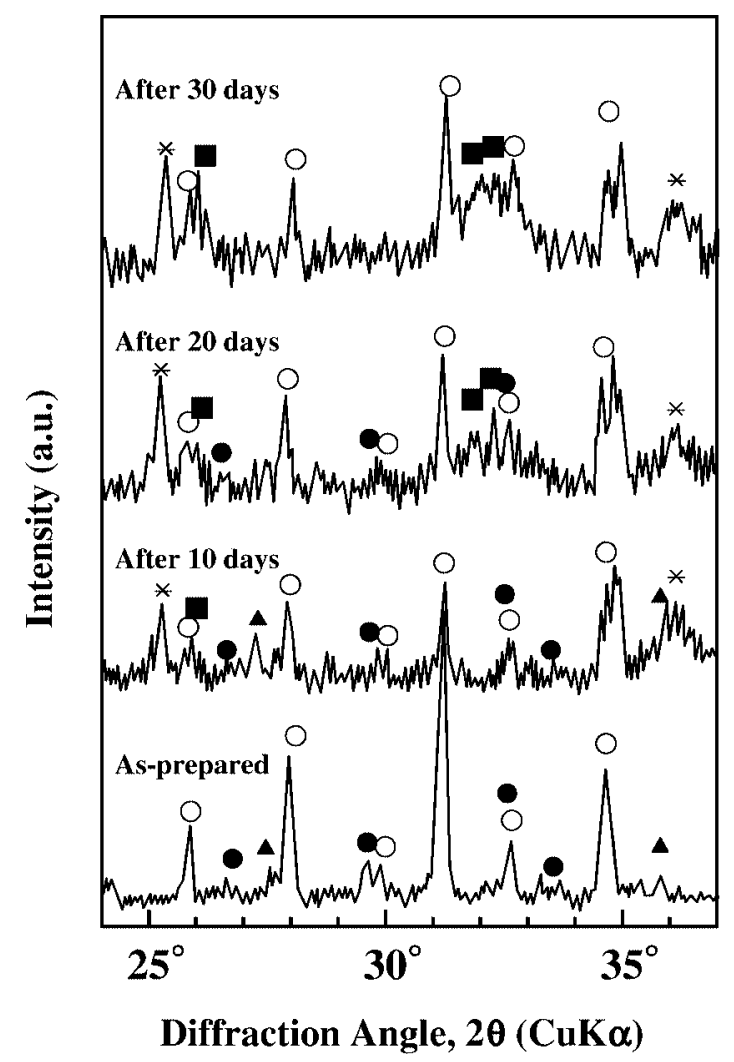

Fig. 13 X-ray diffraction pattern of the surface of the glass-ceramic layer coated on the lloy before or after soaking in SBF for 10, 20 or 30 days; HA, $\bigcirc$ : TCP, 0 : CPP, $\boldsymbol{\Delta}$ : $\mathrm{TiO}_{2}$, and $*$ : unknown phase.

of the coating after 30 days soaking as shown in Fig. 14. The new product formed on the surface of the coating after the soaking is considered to be a calcium phosphate phase such as HA. The result implies a possibility for the glass-ceramic coating on the substrate shows bioactivity in a living body.
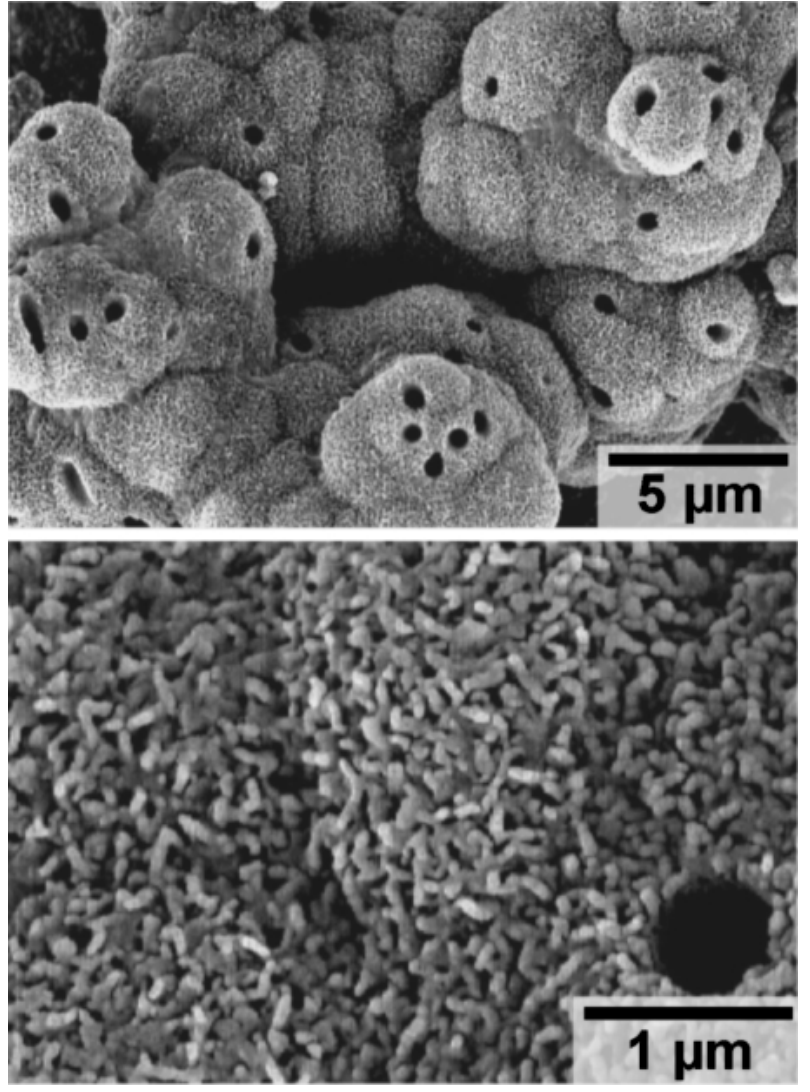

Fig. 14 SEM micrograph of surface of coating after 30 days soaking in SBF; upper and lower ones are taken at high and low magnifications, respectively.

\section{Conclusions}

Low rigidity $\beta$ type titanium alloy composed of non-toxic and non-allergic elements of $\mathrm{Nb}$, Ta and $\mathrm{Zr}$, Ti-29Nb-13Ta4.6Zr, for biomedical applications was designed in this study. Then, the basic mechanical biocompatibility and biological biocompatibility of practical level $\mathrm{Ti}-29 \mathrm{Nb}-13 \mathrm{Ta}-4.6 \mathrm{Zr}$ were investigated. The following results were obtained.

(1) The practical level ingot of $\mathrm{Ti}-29 \mathrm{Nb}-13 \mathrm{Ta}-4.6 \mathrm{Zr}$ is successfully fabricated in this study.

(2) The balance of strength and ductility of Ti-29Nb$13 \mathrm{Ta}-4.6 \mathrm{Zr}$ is equivalent to or better than those of $\mathrm{Ti}-6 \mathrm{Al}-4 \mathrm{~V}$ ELI by aging treatment.

(3) The fatigue strength of $\mathrm{Ti}-29 \mathrm{Nb}-13 \mathrm{Ta}-4.6 \mathrm{Zr}$ is equivalent to that of Ti-6Al-4V.

(4) Young's modulus of $\mathrm{Ti}-29 \mathrm{Nb}-13 \mathrm{Ta}-4.6 \mathrm{Zr}$ is much smaller than that of Ti-6Al-4V ELI.

(5) $\omega$ phase precipitates or both $\omega$ and $\alpha$ phases precipitates in $\beta$ phase in Ti-29Nb-13Ta- 4 aged after solution treatment at a temperature between $573 \mathrm{~K}$ and $673 \mathrm{~K}$.

(6) The strength of $\mathrm{Ti}-29 \mathrm{Nb}-13 \mathrm{Ta}-4.6 \mathrm{Zr}$ can be increased by cold working without increasing Young's modulus.

(7) The biocompatibility of $\mathrm{Ti}-29 \mathrm{Nb}-13 \mathrm{Ta}-4.6 \mathrm{Zr}$ with bone is better than that of SUS 316 stainless steel or Ti-6Al$4 \mathrm{~V}$.

(8) The low rigidity $\mathrm{Ti}-29 \mathrm{Nb}-13 \mathrm{Ta}-4.6 \mathrm{Zr}$ enhances the healing of bone fracture and remodeling of bone. 
(9) The bioactive calcium phosphate coating layer can be formed strongly on $\mathrm{Ti}-29 \mathrm{Nb}-13 \mathrm{Ta}-4.6 \mathrm{Zr}$ by heating $\mathrm{Ti}-$ $29 \mathrm{Nb}-13 \mathrm{Ta}-4.6 \mathrm{Zr}$ coated with invert glasses.

(10) HA is formed on the surface by soaking the calcium phosphate coated $\mathrm{Ti}-29 \mathrm{Nb}-13 \mathrm{Ta}-4.6 \mathrm{Zr}$ in SBF.

\section{Acknowledgements}

Some parts of this study are supported by NED (New Energy and Industrial Technology Development Organization, Tokyo, Japan), Grant-in-Aid for Promoting Scientific Frontier Research from Ministry Education, Science and Culture (Tokyo, Japan), Grant-in-Aide for Scientific Research from Japan Society for Promotion of Science (Tokyo, Japan), Mitsubishi Foundation (Tokyo, Japan), Totai Foundation (Toyohashi, Japan), The Iron and Steel Institute of Japan (Tokyo, Japan), The Light Metal Education Foundation (Osaka, Japan), and Suzuki Foundation (Hamamatsu, Japan).

\section{REFERENCES}

1) ASTM designation F2066-01: Standard specification for wrought titanium-15 molybdenum alloy for surgical implant applications, (ASTM, Philadelphia. PA: U.S.A., 2001) pp. 1605-1608.

2) ASTM designation draft \#3. Standard specification for wrought taitanium-35Niobium-7zirconium-5tantalum alloy for surgical implant applications (UNS R58350): (ASTM, Philadephia. PA, U.S.A).

3) ASTM designation draft \#6. Standard specification for wrought titanium-3aluminun-2.5vanadium alloy seamless tubing for surgical implant applications (UNS R56320): (ASTM, Philadelphia, PA, U.S.A).

4) Y. Okazaki, T. Tateishi and Y. Ito: Mater. Trans., JIM 38 (1997) 78-84.

5) D. Kuroda, M. Niinomi, M. Morinaga, Y. Kato and T. Yashiro: Mater. Sci. Eng. A A243 (1998) 244-249.

6) M. Niinomi: Metall. Mater. Trans. A 33A (2002) 477-486.

7) H. Kawahara, S. Ochi, K. Tanetani, K. Kato, M. Isogai, Y. Mizuno, H. Yamamoto and A. Yamaguchi: J. Jpn. Soc. Dent. Apparat. \& Mater 4 (1963) 65-75.

8) S. G. Steinemann: Evaluation of biomaterials, ed. by G. D. Winter, J. L. Leray and K. de Groot, K (John Wiley \& Sons Ltd., New York, U.S.A., 1980) pp. 1-34.

9) M. Morinaga, M. Kato, T. Kamimura, M. Fukumoto, I. Harada and K. Kubo: Proc. Titanium'92: Science and Technology Vol. 1, ed. by F. H. Froes (TMS, Warrendale, PA, U.S.A., 1993) pp. 217-224.

10) N. Demukai: Proc. 4th Pacific Rim Int. Comf. on Advanced Materials and Processing (PRICM4) (The Japan Institute of Metals, 2001) pp. 369-372.

11) T. Kasuga and Y. Abe: J. Mater. Res. 13 (1998) 70-74. 